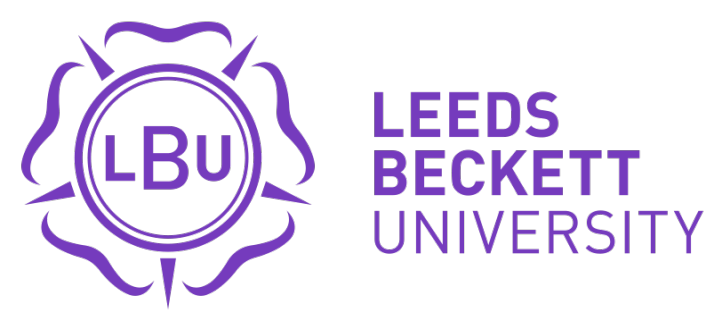

Citation:

McNally, K and Seay, T and Thompson, PA (2019) What the Masters Teach Us: Multitrack Audio Archives and Popular Music Education. In: The Bloomsbury Handbook of Popular Music Education Perspectives and Practices. Bloomsbury, London, pp. 113-126. ISBN 9781350049413

Link to Leeds Beckett Repository record:

https://eprints.leedsbeckett.ac.uk/id/eprint/5903/

Document Version:

Book Section (Accepted Version)

The aim of the Leeds Beckett Repository is to provide open access to our research, as required by funder policies and permitted by publishers and copyright law.

The Leeds Beckett repository holds a wide range of publications, each of which has been checked for copyright and the relevant embargo period has been applied by the Research Services team.

We operate on a standard take-down policy. If you are the author or publisher of an output and you would like it removed from the repository, please contact us and we will investigate on a case-by-case basis.

Each thesis in the repository has been cleared where necessary by the author for third party copyright. If you would like a thesis to be removed from the repository or believe there is an issue with copyright, please contact us on openaccess@leedsbeckett.ac.uk and we will investigate on a case-by-case basis. 


\title{
8 \\ What the Masters Teach Us: Multitrack Audio Archives and Popular Music Education
}

\author{
Kirk McNally, Toby Seay, and Paul Thompson
}

\section{Introduction}

Studies have shown that the recording studio sector has suffered a significant decline within the broader musical economies (Leyshon 2009), which has in turn affected popular music education and specifically the area of music production. For example, the continued loss of many larger recording studio facilities has resulted in fewer internship and apprenticeship opportunities for students, once a pillar of many music production programs. Perhaps more important is the fragmentation of the knowledge capitol that was traditionally found in larger recording facilities. Evidence that this knowledge is still valued by the broader community abounds on the internet, with any number of tutorials by commercially successful and historically significant engineers or producers on " how to give your mix more punch" or "tips on recording drums like a pro." Indeed, entire business models are built upon providing a virtual studio experience and allowing consumers to access the knowledge, skills, and materials associated with that space. A prominent example of this practice is the Shaking Through online series offered by Weathervane Music, a recording studio based in Philadelphia. Their multimedia website consists of episodes centered on an artist or a band as they record a new song, and subscribers can watch documentarystyle videos of the band recording in the studio, along with a traditional music video (Weathervane Music 2014). The multitrack audio from the sessions is available to download alongside other material such as mix stems and recording notes. The recordings are advertised by Weathervane as "high-end" and "professionally recorded," and subscribers are encouraged to create and share their own mixes of the song so they can receive feedback, critique, and encouragement from the studio's in-house mix engineers. 
Identified as both a temple (Cogan and Clark 2003) and laboratory (Hennion 1989), the recording studio was historically the place where the very best musicians, producers, and engineers came to create music recordings. The apprenticeship model of learning within the commercial recording industry allowed student engineers to learn from the masters of their craft and created famous lineages of music producers and engineers; the family tree of George Martin, Geoff Emerick, and Ken Scott at EMI's Abbey Road is perhaps the most well known. Interviewed for this chapter, Ken Scott represents one way that popular music education can tap into this well of historical knowledge, and how moving a "master" into the classroom makes access to their knowledge and ways of working more accessible. However, employing an engineer or producer, such as Scott, in the classroom is a rare opportunity, and beyond the issue of availability of experienced practitioners, there is also the increasing likelihood that they will retire, or join those who have already left us, before their knowledge and experience can be passed on. When a recording is viewed as a cultural, musical, and social artifact, what cultural knowledge remains when the masters are gone? The legacy of their work is found in the music that they have helped to create. This music exists in the forms we commonly associate with recorded music: vinyl records, CDs, or digital downloads. Of course, these versions stand alone, and are polished and pristine in their presentation of the music, but they have a limited ability to help us understand how the recordings were actually made. Primary sources that can help us to understand the creative and technical approaches used during the recording process are the multitrack audiotapes from the recording sessions. A multitrack audiotape contains separate channels of audio and allows the engineer to record sound sources independently from one another. Using this format, a guitar may be recorded onto one track, with bass, keyboards, and vocals each being recorded to other audio tracks and later manipulated and combined during the mixing process. These primary sources, the multitrack audiotapes and the archives that hold them, are an emergent resource for both scholars and students in the field of popular music. This chapter spotlights the way in which three institutions, Drexel University in Philadelphia, USA, the University of Victoria in British Columbia, Canada, and Leeds Beckett University in Leeds, UK, are using multitrack materials in the classroom as part of their music production programs.

\section{Study design}

The chapter uses a qualitative case study design (Yin 2013), principally because it provided a unique way of exploring empirically the use of multitrack master recordings within three specific educational contexts (Dubois and Gadde 2002: 555). Using multiple sources of evidence enables cross-case patterning (Eisenhardt 1989) to determine common structural, historical, cultural, or educational issues within each case. The research data for the three cases includes course materials, student work, student 
feedback, responses from semi-structured interviews, author and instructor reflections and introspections, and a range of multitrack master recordings. As stakeholders within the process, each of the authors presents their specific case, within the context of their particular location and at their relative higher education institution (Eisenhardt and Graebner 2007; Silverman 2006). However, to ensure consistency in analysis of the study's outcomes, each case was constructed using Patton's (2002) three-step model.

This first involved arranging the data for analysis and determining the research questions. Next, the data was grouped and organized in an attempt to develop themes for analysis. Finally, each case was structured and presented in relation to the themes identified at the second step. Where possible, and for ease of comprehension, the research data has been integrated into the discussion within each case.

\section{Case study 1: Drexel University}

\section{Drexel University Audio Archives and Music Industry Program}

The Drexel University Audio Archives is home to the Sigma Sound Studios Collection. Unique to university archives, this collection contains approximately 7,000 popular music productions from the legendary, but now defunct, Sigma Sound Studios, which operated in Philadelphia from 1968 to 2003. Sigma was the predominant site of music production in Philadelphia and where Kenneth Gamble, Leon Huff, Thom Bell, and many others created what became known as "Philly Soul." The collection contains recordings from luminaries such as Teddy Pendergrass, Pattie Labelle, and Grover Washington, Jr., but also recordings of unreleased tracks, outtakes, obscure artists, and from a diverse range of musical styles and genres. Traditionally, materials of this type would not be available to researchers, as they would be held for commercial exploitation (Caw 2004: 50) by record labels and are therefore rare. This collection was donated to Drexel's Music Industry Program with two goals: to preserve the materials and to serve as research sources for music production students. Roughly half of the collection are multitrack audiotapes ranging from four to forty-eight tracks, and the ability to dissect these recordings into their individual sonic elements can offer valuable insight into record production practices (Seay 2011). This collection provides many research opportunities for students to explore, such as explorations of music production practices over time, instrumental arrangements, technical practices, audiovisual preservation issues, and many others. The Sigma Collection is under the purview of Drexel University's Music Industry Program, an undergraduate program with approximately 250 students, which offers music and business education, and allows students to focus their studies on either music business or music production. Multitrack materials have been used in two music production courses with very different goals. 


\section{Uncovering the Philly Groove}

One of the first music industry courses at Drexel to use multitrack materials was Mixing and Mastering.1 Since the acquisition of the archive, multitrack materials from the Sigma Collection are utilized by students to practice mixing, and stereo recordings from the Sigma Collection were used by students to practice their mastering skills. A variety of recordings were selected from the audio archives (by staff) to give students a choice of material to work with (Drexel University, Westphal College of Media Arts \& Design n.d.). Students completed assignments in a variety of ways, including mixing within a digital audio workstation (DAW), mixing with analog tape, and mixing in surround. Whilst useful in providing material to mix and master, unsurprisingly students who have taken this course showed more interest in the iterative processes involved in mixing and mastering (as these processes are taught as part of their program) rather than exploring the content of the multitrack materials. 2 The intent was to use multitrack recordings from the Sigma Collection "as a means to provide aspiring sound engineers with access to knowledge and experience that studio apprenticeships once offered" (Porcello 2004: 737). However, this knowledge and experience can be difficult to explore, as the specific recording process captured on a 40-year-old tape remains hidden. One can speculate and posit theories of production from track organization, leakage (microphone spill), and track bouncing but any "findings" are always based on educated guesses. It was for this reason that a more encompassing project was sought for the use of the archive's multitrack materials.

In 2014, a partnership between the audio archives, MAD Dragon Music Group (Drexel University's entertainment services group, incorporating a record label, a media/marketing arm, a live promotions arm, and a music publishing service), and Reservoir Media (a private media and publishing company based in New York) led to the creation of a new independent study course (Mad Dragon Music n.d.; "Drexel Unveils New Philly Groove Mixes (+ video)" 2015).3 This new course "Uncovering the Philly Groove" involved eight music production students and the MAD Dragon Music Group class and our intention was for it to explore rare recordings within the audio archives (owned by Reservoir Media) from technical, commercial, and cultural perspectives.

This course was structured so that the music production students provided mixes for Reservoir Media (for their internal purposes), while the MAD Dragon Music Group students created a marketing plan and narrative for the recordings as if the mixes were a commercial album release. The result was engagement with the local recording community (through panel discussions, professional visits, and public lectures by the engineers, musicians, and artists who created the original material that the students were working with). The music production students were each given two songs to mix. During the course, they were required to perform file management, capture metadata (for cataloging purposes), and work on their mixes with weekly critiques from music 
production faculty. Student comments were garnered from a survey upon completion of the course and were overwhelmingly positive:

This was one of the more interesting classes/projects I was able to participate in. Projects in some of my other classes aren't completely relevant to the music industry outside class, but being a part of this project allowed me to be a part of mixing a record that might have actually come out. (DU student one)

I enjoyed the change between having isolation and having more of an ensemble feel only having so many tracks to work with in having a full arrangement. It's a lot nicer to mix that way as everything exists together. (DU student two)

These student comments differ greatly from the following comments about the Mixing and Mastering course, which are generally more negative and unfocused:

Maybe pick some sessions (if you can get them) of songs that we already know very well (popular) so we can mix/ master them differently. (DU student three)

The in-class critique was nice, but why doesn't our program have more one-on-one with a professor, ripapartour-mix time? (DU student four)

These differences in student comments point to the Uncovering the Philly Groove course as having a more successful approach in making a connection between technique and the audio content. The instructor noted that students were willing to spend significantly more time on each assignment in the Uncovering the Philly Groove course than in Mixing and Mastering. The more focused approach to mixing and each student's engagement with a larger team created a high amount of "buy-in" to the assignment. Due to the one-on-one critiques, it was much easier to delve into recording practices as evinced by the multitrack recordings. For instance, many students struggled with drum tracks where the overhead mics, tom mics, and snare mic were combined to one track. Students often wanted to manipulate one of these elements but did not have the isolation to do so. This situation initiated a discussion about priorities and compromises (often imposed by technical or financial limitations) that exposed such relationships within the music production process.

Additionally, a common point of discussion was in regard to the level of reverence for the materials and whether or not the students should employ modern mixing tools that were unavailable at the time of creation, or whether they should try to stay true to a vintage production aesthetic. While many of the students tried to be more modern with their mixes, most felt that the multitrack recordings led them to a more vintage approach, thus solidifying the concept of a sonic signature of the recording practices utilized at Sigma Sound Studios (Davis 2009; Seay 2016). 


\section{Case study 2: University of Victoria}

\section{The School of Music and the KLÖ audio archive}

Located in Victoria, British Columbia, on the west coast of Canada, the University of Victoria is a public research university that is home to the School of Music and the KLÖ audio archive. The school has a student body of approximately 250 students madevup of both undergraduate and graduate students. The undergraduate curriculum designvis based on the conservatory model, where individual studio instruction is supportedvby musicianship, music theory, and music history courses. The music productionvcourses that utilize the KLÖ archive and are examined in this case were designed with undergraduate and graduate students in mind whose majors may include: music composition, performance, music technology, or music and computer science.

The band KLÖ was a prominent member in the burgeoning art-rock scene in Toronto in the early 1980s, and became known for their angular rhythmic style and experimental use of percussion instruments. The band had the good fortune of a benefactor who funded recordings in New York and San Francisco at Skyline Recording Studios (Skyline Studios Pro n.d.) and CD Present (Records), 4 respectively. These recordings were made with significant engineers and producers, and this work is represented in the archive. 5

The KLÖ archive was donated to the School of Music in 2014 and includes ephemera and a collection of multitrack and half-inch stereo master tapes, which represents the majority of the band's recorded history. Now digitized, the entire collection includes recording sessions undertaken in Toronto, Hamilton, San Francisco, and New York. The recordings span the lifetime of the band, from their inception in 1979 to their break-up in 1986, and while the commercial success of KLÖ was admittedly limited, the access and associations made possible by the financial support of the band's benefactor makes for an interesting and useful archive. With KLÖ working at significant studios, and with engineers and producers that represented the popular sound of an era, music scenes, and geographic location (Gibson 2005) the archive provides unique opportunities for study and use within the context of music production education.

\section{KLÖ in the classroom}

The KLÖ tapes are used at the University of Victoria as both a source for analysis as well as a practical ear training tool. This approach builds upon both the technical ear training (TET) methods (Corey 2012), or the so-called Golden Ears (Moulton 2013) ear training programs, and the apprenticeship and critique-based training model historically used in the industry sector. By measuring objective audio features and creating new ways of visualizing this data, the method attempts to reveal the training, craft, and artistry of the engineers and producers captured on the master tapes, using this to guide 
student learning and skills development. Where TET systems train for identification and replication in isolation (frequency and equalization, dynamic range, reverberation, and technical errors), the University of Victoria approach focuses on performance and technical changes made over the course of - or between two-music productions. It is an epistemological approach, providing the student with information that helps reveal what the intentions of the engineer and producer were. Within the KLÖ archive it is possible to follow the entire production timeline, from demo recordings, through basic takes and overdubs, to the final product. The intermediary in all these steps is the engineer and producer and their sonic signature - the culmination of their training and experience at that time - is leveraged for educational purposes in a number of ways. A useful example of this approach is a fourth year music production assignment where students are tasked with replacing the drums on one of the KLÖ multitracks.

An instructor-led discussion precedes the recording session where students are first encouraged to listen critically to the audio material. They are then given visual aids showing the tempo analysis of the drum performances for three takes of the same song. In this way they see the performance and then listen for performance features such as rhythm and timing. When repeated for multiple takes patterns develop that help students understand the engineer, producer, and band's decisions as to what constituted the "best" performance. Delving further into the material, comprehensive audio analysis (Peeters 2004) is used to characterize the different drum sounds found on the original recording. Again, the progression of the sound across the three takes is visualized and used to guide student listening. The students are given evidence of how the production team arrived at their final sound, as well as a clear, measurable set of parameters and a useful framework that they can use when they approach rerecording the drums. For example, seeing and listening to how the tempo becomes more consistent with subsequent takes, or perhaps that the snare drum sound becomes increasingly focused in a specific frequency band, provides students with a virtual apprenticeship experience, which hopefully helps them to better understand the processes of decision-making in the recording studio and how experienced engineers and producers work through an iterative process to achieve a desired sound in a music production.

Evidence of the students' engagement and their subsequent development of new skills using this approach was seen in student comments, taken from course experience surveys administered at the conclusion of all courses offered at the University of Victoria:

Going to the studio and working with real recordings (KLÖ) was really fun and felt relevant. (UVic student one)

Availability of multitrack archive recordings presents a concrete, exact example of recording techniques in popular music for the students to use and manipulate, offering more insight into the techniques and sound for 
individual audio tracks than simply analyzing a fully mastered and mixed down pop music recording could. (UVic student two) I think more of a focus on contemporary techniques first would help contextualize the KLÖ tapes and make it easier for the students to see the relevance of the skills to their pursuits. (UVic student four) It was clear from student comments that they saw the value of having a concrete example of a music production for the sake of analysis and manipulation. Having access to multiple takes of a song was commonly discussed and identified as a very positive feature of this archive, with students expressing an increased appreciation for how much a seemingly small change, either technical or in the performance, can have on the larger musical work.

A number of student comments focused on the historical nature of the archive, where they identified that the era specific production techniques and approaches were either difficult to emulate, incorporate, or were not relevant to their own contemporary music productions. Relating to this point, the drum rerecording assignment (mentioned above) was both identified as a highlight and frustrating for students, as they struggled to match the drum sounds - admittedly a very difficult task given the number of variables present. While not the primary goal of this assignment, discussion regarding the differences between contemporary recording technology and the equipment used on the archival recordings further engaged students with the material, and again points to the value of using primary sources for music production education.

\section{Case study 3: Leeds Beckett University}

\section{Audio and music programs at Leeds Beckett University and Ken Scott's audio archive}

As with most educational institutions, Leeds Beckett University does not have a dedicated archive of physical or digital multitrack recordings. Rather, historic and notable multitrack recordings within the popular music canon are introduced to students through associate lecturer Ken Scott. Beginning his apprenticeship at EMI's Abbey Road recording studios in 1964, Scott began working in the studio with artists such as Manfred Mann, The Hollies, and Judy Garland. In 1967 Scott was promoted to engineer and worked most notably with The Beatles. After leaving Abbey Road to work as a freelance engineer and producer in 1969, Scott worked with Elton John, John Lennon, Ringo Starr, George Harrison, David Bowie, and Supertramp. Working with so many commercially successful and critically acclaimed artists has allowed him to develop 
his own multitrack recording archive. Scott's personal archive provides a unique opportunity to introduce students to the multitrack recordings of well-known records by the person who directly contributed to their creation. Scott lectures on audio recording and studio-based modules that are contained within Leeds Beckett University's suite of audio and music programs (BSc Audio Engineering, BSc Music Technology, BA Music Production, and BA Music Production and Performance).

\section{The use of multitracks}

Scott has developed his multitrack archive over the last thirty years and some items have been digitized (often for remix projects) during this time, notably David Bowie's "Life on Mars." The multitracks form part of the historic knowledge at a particular point in time in British record production, as Scott states:

I was working in Abbey Road with Duran Duran on the "Thank You" album and me and the maintenance guy were chatting and he said "do you remember when we first started we were told all of these incredible stories by the old timers", I said "yeh, it was amazing". He said "well now we've become them, the younger ones want to hear our stories" and that got me thinking ... Multitracks can teach students what it used to be like, in every way, from a performance standpoint to an engineering standpoint.7

Ken views mutlitracks as a useful tool for audio education to gain a different perspective on sound recordings:

People have heard the finished recording, but the engineers, the students and the fans want to hear what the finished product comprises of, and hear it in a way that only us in the studio have ever heard it.

The stories that accompany the creation of the multitrack recording are also a fundamental part of using multitracks:

I use stories to give some background and to make a particular point. It's not necessarily that I can teach any more than anyone else with a multitrack because I've spoken to enough educators to know that we're all trying to push the same agenda, but because I was there they [students] tend to listen that much more and it means more to them. 
Scott's approach to using multitracks in the lecture theater focuses on listening to snippets of the multitrack with a particular focus on one specific topic. This is done for two reasons: (1) some of the rights holders for the multitracks were concerned that parts of it could be sampled if the lecture was recorded in some way. Using short sections, or adding a commentary over the section of audio, satisfies the rights holders, and (2) using one part at a time helps to focus the discussion on one specific element of the multitrack. For example, Ken might focus on one instrument in a production such as electric guitar:

Soloing a guitar brings out some of the noise of the amp and students are always amazed at how noisy it is. I use these examples to show that any hum from guitars is generally cancelled out by the bass, any hiss is cancelled out by cymbals so you don't hear it when it's in the mix.

This approach also allows him to focus on some of the musical aspects of the recordings such as arrangements and performances:

It's the performance side of things that technology is pulling away from people, y'know "I'll sing the chorus once and you can copy and paste it" ... being able to play one of David Bowie's vocals, one-take from beginning to end, really helps to put across the importance of performance.

\section{Using multitracks in the recording studio}

In the recording studio, Scott uses the multitracks with an analog mixing console in order to show students how he works on the desk:

I know from my perspective that more is learnt by seeing me work than by anything else. That's why, in the studio, I bring up the multitracks through the desk whilst students are watching.

He uses multitracks to emphasize the importance of getting sounds before they are recorded to tape or Pro Tools:

In my mixing class I use the multitrack for "Rock n Roll Suicide." I told them beforehand that one of the reasons that I get the finished product that I do is because I get the sounds I want right from the beginning. I EQ going onto tape or into Pro Tools. It's great, it means I can pull up "Rock n Roll Suicide," play them the whole thing and it sounded almost like the record without any EQ, nothing. The only thing I did was ride the vocal a bit.

Scott also uses multitracks to teach his process of mixing, focusing on his use of the console as a performance: 
I can't mix in the box, it's just not what I'm used to. A mix for me is a performance and I think it's important to reiterate to students that the mixing desk is my instrument and it can be used as an instrument.

In each situation, however, multitracks are not used on their own, they are often used alongside the finished recording:

As long as you move on and play the final thing, that's important. For me the drums on "Life on Mars," they're dead and I added single repeat tape echo to them, which gives them a bit more life. So, get back to the finished recording, make sure they [students] hear it that way.

\section{Outcomes}

Scott's use of multitracks in both the lecture theater and the recording studio has had some useful positive outcomes. Importantly, students identify that it is not only the materials but the interaction of an experienced engineer with this type of resource that provides significant learning opportunities:

One of the students at the end of one session came up to me and said "I took one of your classes last year and you said about looking versus listening." He said that he's now started listening as opposed to looking. "It's made such a difference to my mixes, thank you so much" and that makes it all worth it.

While it is clear that not every program will have access to a Ken Scott figure, the learning possibilities that multitrack materials provide can be found in unlikely ways:

In my mixing class, there's a girl who was a singer and she noticed I was riding the fader for the vocal. After the class, she came up to me and asked about it. It's doing things like that, that students get more from just talking about it, and they get to see how I work.

\section{Analysis and conclusions}


The three cases presented here show that multitrack materials can be used in various contexts for different educational purposes and outcomes. Primarily, they can be used in the development of practical skills such as mixing and mastering. The Drexel University case highlights how the use of high quality multitrack recordings can provide students the opportunity to practice mixing with well-engineered recordings. However, students benefited most when the mixing process was part of a larger project involving multiple stakeholders within a notable historical context. In that context, they were able to develop a deeper appreciation for the relationships that exist between the initial stages of recording and the final processes involved in record production such as mixing.

Multitrack materials can also be used for the purpose of analysis. For example, the University of Victoria case shows how multitrack materials, in combination with analysis frameworks, can be an effective way of engaging students in critical listening. By placing analysis at the front of the production process, and listening to different takes of the same song, the students can begin to develop a more critical approach to their own recordings when trying to achieve a particular sound. The "Uncovering the Philly Groove" project at Drexel University and Ken Scott's work at Leeds Beckett University show that students gain a more comprehensive picture of the production processes behind the recordings when they have a connection to the creators who contributed to the multitrack materials. It shows that engaging the voices and perspectives of those involved with the productions has helped to uncover processes that are not evident in the final recording or within the multitrack elements.

Finally, these three cases show that there is a strong historical element to the current institutional multitrack holdings. With an equal focus on the performances captured on the multitracks, and the techniques employed by the engineers and producers who made them, it is possible to illuminate some of the nuances of music production at specific geographic locations in the history of recorded music. Consequently, there exists a real opportunity to both learn from our past masters by using the methods identified in the individual cases and to use them to inform production practices in contemporary contexts. Nearly all existing multitracks were never intended for educational use - rather, these materials were archived within a commercial creation production process that was not concerned with making educational or historical resources. With an eye to the future, and in response to the call from students, the development of contemporary multitrack resources should be a growing priority for educators involved in music production education. Attention must be given to creating diverse multitrack collections that can represent the voices of multiple master engineers and producers from all genders, genres, and cultures. Unlike the majority of openly available multitrack resources, any new resources should include out-takes or alternate versions of recordings. As was illustrated in the University of Victoria case, this commonly omitted material can provide a far richer learning experience for students when it is included in

the archive. With so many commercial and practical constraints, it may be a tall order 
but with enough institutional, economic, and educational impetus, the authors believe that this can be achieved. As the economy of the popular music industries continues to shift, so too should the educators and programs that teach the next generation of musicvproduction students.

\section{Notes}

1 MIP481 Mixing and Mastering. Description: "The art of mixing and mastering music is covered in depth. This is an advanced audio engineering course that will focus on the mixing and mastering process. Proper equipment usage, methods, formats, and production goals are covered" (Drexel University 2018).

2 An interesting observation: students often found the archival multitrack recordings rather easy to blend musically. The useful lesson here is that the process of mixing starts at the beginning of the recording process, in the selection and placement of microphones to capture a well delivered performance.

3 An independent study course is a self-directed module within a specific area of study requiring intermittent consultation with a designated instructor.

4 David Ferguson founded CD Presents as an independent concert production company in 1979, transforming CD Presents (Records) into a powerhouse independent label and recording studio in 1981, with releases from bands including: The Avengers, Circle Jerks, D.O.A, The Subhumans, and Butthole Surfers.

5 For example, Jack Nuber, engineer on the Skyline recordings, has engineering credits including The Talking Heads, Dire Straits and Robert Palmer.

6 There are approximately 500 undergraduate students studying across these programs and a focus on studio recording and production is common throughout.

7 All quotes for this case are attributed to Ken Scott, taken from an interview with the author, November 24, 2017.

\section{References}

Caw, Tom S. (2004), "Popular Music Studies Information Needs: You Just Might Find ...,’’Popular Music and Society, 27 (1): 49-54.

Clark, William and Jim Cogan (2003), Temples of Sound: Inside the Great Recording Studios, San Francisco: Chronicle Books.

Corey, Jason (2013), Audio Production and Critical Listening: Technical Ear Training, Burlington, MA: Focal Press.

Davis, Robert (2009), "Creative Ownership and the Case of the Sonic Signature or, 'I'm Listening to this Record and Wondering Whodunit?'," Journal on the Art of Record Production, (4).

Drexel University, Westphal College of Media Arts \& Design (n.d.), "Drexel University Audio Archives." Available online: http://drexel.edu/westphal/academics/undergraduate/MIP/

SigmaSoundArchives (accessed November 16, 2018).

Drexel University (2018), "Search Results: MIP 481 Mixing and Mastering 3.0 
Credits."Available online:

http://catalog.drexel.edu/search/?P=Mixing+and+Mastering (accessed November 17, 2018).

"Drexel Unveils New Philly Groove Mixes (+ video)" (2015), Reservoir Media, March 3, 2015.

Available online: www.reservoir-media.com/news/post/MTM5NzYtZjNkM2Fi (accessed November 16, 2018).

Dubois, Anna and Lars-Erik Gadde (2002), "Systematic Combining: An Abductive Approach to Case Research," Journal of Business Research, 55 (7): 553-560.

Eisenhardt, Kathleen M. (1989), "Building Theories from Case Study Research," Academy of Management Review, 14 (4): 532-550.

Eisenhardt, Kathleen M. and Melissa E. Graebner (2007), "Theory Building from Cases: Opportunities and Challenges," Academy of Management Journal, 50 (1): $25-32$.

Gibson, Chris (2005), "Recording Studios: Relational Spaces of Creativity in the City," Built Environment, 31 (3): 192-207.

Hennion, Antoine (1989), "An Intermediary Between Production and Consumption: The Producer of Popular Music," Science, Technology \& Human Values, 14 (4): 400-424.

Leyshon, Andrew (2009), "The Software Slump?: Digital Music, the Democratisation of Technology, and the Decline of the Recording Studio Sector within the Musical Economy," Environment and Planning A, 41 (6): 1309-1331.

Mad Dragon Music (n.d.). Available online: www.maddragonmusic.com/ (accessed November 16, 2018).

Moulton, David (2013), Golden Ears: An Audio Ear-Training Course for Recording Engineers, Producers and Musicians, KIQ productions, 8 compact discs.

Patton, Michael Quinn (2002), Qualitative Research and Evaluation Methods, third edition, Thousand Oaks, CA: Sage Publications Inc.

Peeters, Geoffroy (2004), A Large Set of Audio Features for Sound Description (Similarity and Classification) in the CUIDADO Project, Paris: Ircam.

Porcello, Thomas (2004), "Speaking of Sound Language and the Professionalization of Sound-Recording Engineers," Social Studies of Science, 34 (5): 733-758.

Seay, Toby (2011), "Primary Sources in Music Production Research and Education: Using the Drexel University Audio Archives as an Institutional Model," Journal on the Art of Record Production, (5).

Seay, Toby (2016), "Sonic Signatures in Record Production," in Jenns Gerrit Papenburg and Holger Schulze (eds), Sound As Popular Culture, 347-354, Boston, MA: MIT Press.

Silverman, David (2006), Interpreting Qualitative Data: Methods for Analyzing Talk, Text and Interaction, London: Sage Publications Inc.

Skyline Studios Pro (n.d.), "Skyline Studios, NYC (Studio 6 Shown).” Available online: www.skylinepro.com/skyline_studios.html (accessed November 16, 2018).

Weathervane Music (2014), Shaking Through. Available online: https://weathervanemusic.org/ shakingthrough (accessed November 16, 2018).

Yin, Robert K. (2013), Case Study Research: Design and Methods, Thousand Oaks: Sage Publications Inc. 